\title{
Toxicidade de bebidas lácteas achocolatadas do tipo não fermentadas frente a tecido de intensa proliferação celular
}

\author{
Milk drinks toxicity chocolaty type unfermented front intense cell proliferation tissue
}

\author{
Hélia Alencar Martins e Ana Paula Peron
}

Campus Senador Helvídio Nunes de Barros, Universidade Federal do Piauí, PI, Brasil helia.alencar.ufpi@gmail.com;anapaulaperon@ufpi.edu.br

\begin{abstract}
Resumo
Objetivou-se nesse trabalho avaliar a toxicidade aguda em nível celular de bebidas lácteas achocolatadas de cinco empresas de expressiva atuação no mercado de alimentos de países da América do Sul e Europa. Essa avaliação se deu por meio das células meristemáticas de raízes de Allium cepa L., nos tempos de exposição 24 e 48 horas, diretamente nos produtos lácteos comercializados. Com base nos resultados obtidos, verificou-se que todas as amostras de achocolatados analisadas causaram significativa redução do índice mitótico, logo no menor tempo de exposição considerado, e ocasionaram, nos dois tempos de análise estipulados, número estatisticamente significativo de alterações de fuso mitótico e micronúcleos aos meristemas de raízes avaliados. Portanto, nas condições de análise estabelecidas, os achocolatados analisados foram citotóxicos e genotóxicos.
\end{abstract}

Palavras-chave: achocolatados; citotoxicidade; genotoxicidade; tecido meristemático

\section{Abstract}

The objective of this study was to evaluate the acute toxicity at the cellular level of milk chocolate drinks, five significant operations of companies in the food market of countries in South America and Europe. This assessment was through the meristem cells of roots of Allium cepa L., the exposure times 24 and 48 hours, directly in milk products marketed. Based on these results, it was found that all the analyzed chocolate milk samples caused a significant reduction of mitotic index, at the lowest exposure time considered and resulted in both stipulated analysis times statistically significant number of mitotic spindle changes and micronuclei to meristem evaluated roots. Therefore, the established analytical conditions, the chocolate milk were analyzed cytotoxic and genotoxic.

Keywords: milk drinks; cytotoxicity; genotoxicity; meristematic tissue 


\section{Introdução}

As bebidas lácteas achocolatadas, do tipo não fermentadas, são encontradas em todo o mundo e consumidas por pessoas de todas as idades. Tais produtos possuem, em sua formulação básica, constituintes nutricionais, como carboidratos, cálcio, magnésio, ferro, e vitaminas, tais como niacina, B1, B2, B6 e B12, considerados por profissionais da saúde como importantes para o bom funcionamento do organismo (Pflanzer et al., 2010). Ainda, esses alimentos proporcionam conveniência e praticidade em seu consumo frente ao acelerado ritmo atual de vida da população, apresentam excelentes propriedades sensoriais, como cor, odor e sabor atrativos, e são comercializados em embalagens compactas, o que facilita sua estocagem (Batista et al., 2015; Oliveira et al., 2015).

No entanto, para a obtenção das características organolépticas oferecidas atualmente, a composição química original dos achocolatados lácteos não fermentados sofreu diversas alterações desde seu lançamento no mercado no início da década de 90 , dentre as quais a incorporação de classes de aditivos ou microingredientes alimentares sintéticos de ações edulcorantes, aromatizantes, corantes, acidulantes e espessantes (Mirtem et al., 2013). No Brasil, a confecção e comercialização de alimentos lácteos não fermentados é regida pelo Ministério da Agricultura, Pecuária e Abastecimento, por meio da Portaria № 36, de 31 de outubro de 2000, que aprova os regulamentos técnicos para fixação de padrões de identidade e qualidade de bebidas lácteas fermentadas e não fermentadas (Brasil, 2000; Oliveira et al., 2016). Este documento normativo foi construído com base nas determinações do Codex Alimentarius, órgão mundial responsável pelo estabelecimento das normas gerais de formulação química, segurança e rotulagem de alimentos (Pflanzer et al., 2010; Oliveira et al., 2016).

Contudo, há estudos que relacionam os microingredientes a efeitos prejudiciais à saúde de quem os consomem, com destaque ao público infantil. Entre as consequências descritas estão o desenvolvimento ou potencialização de alergias crônicas, distúrbios gastrointestinais e alterações do sistema nervoso central (Gomes et al., 2013; Oliveira et al., 2013; Neves et al., 2013; Moura et al., 2016). Dessa forma, as agências de vigilância alimentar, como o Codex Alimentarius e a European Food Safety Authority (EFSA), ressaltam em seus regulamentos técnicos a necessidade constante de estudos citotoxicológicos de efeito agudo dos aditivos alimentares em geral, e, especialmente, dos alimentos industrializados compostos por eles (Bianchi et al., 2015; Sales et al., 2016). Destacam também que os resultados obtidos destas análises são a base de elaboração ou modificação de estratégias das agências de segurança alimentar e, consequentemente, de atuação dos profissionais responsáveis pela vigilância alimentar e nutricional da população (Moura et al., 2016; Oliveira et al., 2016). Entretanto, em uma ampla busca a literatura científica, verificou-se que não existem trabalhos de avaliação de toxicidade em nível celular de bebidas lácteas industrializadas, em geral.

A região meristemática de raízes de Allium cepa L. (cebola) é tida no meio científico como um eficiente bioensaio para a avaliação da toxicidade aguda em nível celular de compostos químicos em virtude de apresentarem número cromossômico reduzido $(2 \mathrm{n}=16)$, o que facilita a detecção de alterações cromossômicas e de fuso mitótico (Lacerda et al., 2014; Neves et al., 2016). Esse sistema teste é aceito internacionalmente por agências de pesquisa como um instrumento de avaliação de acurada sensibilidade para análise inicial da citotoxicidade, genotoxicidade e mutagenicidade de substância de interesse, uma vez que, os resultados obtidos por meio dele, em grande parte das vezes, demonstram similaridade satisfatória a aqueles obtidos em sistemas testes animais e culturas de células (Türkoğlu, 2007; Herrero et al., 2011; Tabrez et al., 2011; Gomes et al., 2013; Oliveira et al., 2013; Lacerda et al., 2014; Neves et al., 2013; Moura et al., 2016; Oliveira et al., 2016; Santana et al., 2016). Como exemplo pode-se citar os trabalhos realizados por Oliveira et al. (2013) e Gomes et al., (2013) que avaliaram em células meristemáticas de raízes de A. cepa o potencial tóxico de aromatizantes e corantes alimentares sintéticos, respectivamente, e obtiveram resultados semelhantes aos obtidos em sistemas testes animais e com culturas de células.

Conforme descrito por Zilifdar et al. (2014) e Valavanidis et al. (2013), substâncias citotóxicas, genotóxicas e mutagênicas prejudicam mecanismos celulares vitais, como a duplicação e a transcrição gênica, alterando drasticamente a divisão celular de tecidos por meio da indução de aberrações celulares, como as de fuso mitótico e as quebras cromossômicas, e dessa forma desencadear e/ou potencializar processos cancerosos. Segundo Zaineddin et al. (2012), o desenvolvimento dos tipos mais comuns de câncer resulta da interação entre fatores endógenos e ambientais, sendo o mais notável deles a dieta alimentar, principalmente quando constituída de alimentos industrializados em demasia.

Com base no contexto abordado, objetivou-se nesse trabalho avaliar a citotoxicidade e genotoxicidade de produtos lácteos achocolatados, do tipo não fermentados, de cinco companhias alimentícias de relevante atuação no mercado de alimentos em países da América do Sul e Europa, com destaque ao Brasil, através das células meristemáticas de raízes de A. cepa. 


\section{Material e método}

Amostras de achocolatados lácteos industrializados, do tipo não fermentados, fabricados pelas empresas de alimentos Pepsico@ $\odot$, Nestlé@ $\odot$, Maratá $\odot$, Piracanjuba $\odot$ e Embaré@- referidas adiante como A, B, C, D e E, respectivamente -foram adquiridas em mercado varejista na cidade de Picos, Piauí, Brasil. Teve-se o cuidado de verificar se as amostras estavam dentro do prazo de validade e se suas embalagens estavam intactas. As análises de toxicidade foram realizadas diretamente nos produtos lácteos comercializados.

Os bulbos de cebola foram colocados em frascos aerados com água destilada, à temperatura ambiente $\left( \pm 27^{\circ} \mathrm{C}\right)$, até a obtenção de raízes de 2,0 cm de comprimento. Para análise de cada grupo tratamento estabeleceu-se um grupo experimental com cinco bulbos de cebola. Antes de colocar as raízes em contato com as suas respectivas amostras de achocolatados (tratamentos), algumas raízes foram coletadas e fixadas para servirem de controle do próprio bulbo. Em seguida, as raízes restantes foram posta em seus respectivos tratamentos por 24 horas, procedimento denominado de tempo de exposição 24 horas.

Após 24 horas foram retiradas algumas raízes e fixadas. Feito este procedimento, as raízes restantes de cada bulbo foram devolvidas a seus respectivos tratamentos onde permaneceram por mais 24 horas, o que se denominou de tempo de exposição 48 horas. Após este período, raízes novamente foram coletadas e fixadas. Os tempos de exposição 24 e 48 horas foram escolhidos com o intuito de avaliar a ação dos tratamentos em mais de um ciclo celular. A fixação das raízes se deu em Carnoy 3:1 (etanol: ácido acético) por 24 horas. Em cada coleta, retirou-se, em média, três raízes por bulbo.

As lâminas, em média 03 por bulbo, foram feitas seguindo o protocolo proposto por Guerra e Souza (2002), e analisadas em microscópio óptico em objetiva de 400x. Para cada bulbo de cebola analisou-se 1.000 células, totalizando 5.000 células para cada controle, tempo de exposição 24 horas e tempo de exposição 48 horas de cada grupo tratamento em análise. Assim para cada grupo tratamento (amostra de achocolatado) analisou-se um total de 15.000 células. Foram observadas células em interfase, prófase, metáfase, anáfase e telófase. Para o cálculo do índice mitótico (IM) utilizou-se a seguinte equação: (número total de células em mitose $\div$ número total de células analisadas) x 100. Avaliou-se também a toxicidade das amostras de achocolatados por meio da frequência de micronúcleos, metáfases colchícinicas, pontes anáfasicas e telofásicas, amplificações gênicas, células com aderências, brotos nucleares e anáfases multipolares. Para a análise estatística dos dados, utilizou-se o teste do Qui-quadrado ( $\chi 2)$, com nível de probabilidade de erro $<0.05$.

\section{Resultados e discussão}

Com base nos resultados obtidos na Tabela 1, verifica-se que os achocolatados das cinco empresas consideradas causaram expressiva redução no índice mitótico do tecido meristemático analisado, nos dois tempos de exposição considerados, em relação ao observado para seus respectivos controles. No entanto, quando confrontados os índices mitóticos do tempo de exposição $24 \mathrm{~h}$ com os seus respectivos tempos de exposição $48 \mathrm{~h}$, verificou-se que tais alimentos não promoveram redução significativa da divisão celular do tecido analisado, ou seja, o efeito antiproliferativo não é maior com o aumento do tempo de exposição das células ao tratamento com os achocolatados testados

Assim, todas as amostras de achocolatados avaliadas, nas condições de estudos estabelecidas, foram citotóxicas às células meristemáticas de raízes de Allium cepa, por terem ocasionado efeito antiproliferativo acentuado aos meristemas de raízes ao qual foram expostos. De acordo com Gomes et al. (2013), Marques et al., (2015), Sales et al. (2016), Moura et al. (2016) a redução do índice mitótico ocasionada por compostos químicos em tecidos sem nenhum tipo de mutação e/ou alteração celular é prejudicial ao organismo em que ocorrem, em razão de inibir ou limitar a reposição de células, alterar a produção de proteínas e, consequentemente, resultar no mal funcionamento do órgão onde está localizada.

Na Tabela 2 é possível observar que todos os achocolatados, nos dois tempos de exposição considerados, induziram a formação expressiva de alterações de fuso mitótico, representadas no presente estudo pelas metáfases colchicínicas e pontes anáfasicas (alterações representadas na Figura 1) e pontes telófasicas, o que caracteriza as amostras avaliadas, nas condições de análise estabelecidas, como genotóxicas.

As alterações de fuso mitótico quando em frequência significativa causam instabilidade nuclear, dando origem a fragmentos acêntricos ou não, que, em consequência, formarão os micronúcleos ao final da divisão celular. A presença significante de células micronucleadas, como a observada aqui em consequência da ação dos achocolatados, classifica substâncias, compostos ou soluções testadas como genotóxicas (Aissa et al., 2012). Tal condição sugere que os produtos lácteos avaliados neste trabalho devam ser avaliados em sistemas testes animais, uma vez que, de acordo com Queiroz et al. (2013) a ocorrência de alterações celulares, apesar de não ser medida de carcinogenicidade, está frequentemente associada ao aparecimento de câncer, visto que, há correlação positiva entre o aumento 
Tabela 1 - Número de células em cada fase do ciclo celular observadas em tecido meristemático de raízes de Allium cepa tratadas com achocolatados lácteos não fermentados - de cinco empresas alimentícias identificadas como A, B, C, D e E - avaliadas nos tempos de exposição 24 e 48 horas

\begin{tabular}{c|c|c|c|c|c|c|c|c}
\hline \multicolumn{2}{c}{ DADOS ÍNDICE MITÓTICO } \\
\hline Empresa & TE & TCII & $\mathrm{P}$ & $\mathrm{M}$ & $\mathrm{A}$ & $\mathrm{T}$ & TCD & IM $(\%)$ \\
\hline & $\mathrm{CO}$ & 3900 & 450 & 222 & 281 & 147 & 1100 & $22,0 \mathrm{a}$ \\
\hline $\mathrm{A}$ & $24 \mathrm{~h}$ & 4831 & 124 & 119 & 11 & 15 & 269 & $5,4 \mathrm{~b}$ \\
\hline & $48 \mathrm{~h}$ & 4754 & 194 & 26 & 13 & 13 & 246 & $4,9 \mathrm{~b}$ \\
\hline & $\mathrm{CO}$ & 4035 & 340 & 247 & 232 & 146 & 965 & $19,3 \mathrm{a}$ \\
\hline $\mathrm{B}$ & $24 \mathrm{~h}$ & 4726 & 141 & 94 & 26 & 13 & 274 & $5,5 \mathrm{~b}$ \\
\hline & $48 \mathrm{~h}$ & 4850 & 84 & 17 & 27 & 22 & 150 & $3,0 \mathrm{~b}$ \\
\hline & $\mathrm{CO}$ & 3830 & 394 & 254 & 301 & 221 & 1170 & $23,4 \mathrm{a}$ \\
\hline $\mathrm{C}$ & $24 \mathrm{~h}$ & 4720 & 127 & 85 & 45 & 23 & 280 & $5,6 \mathrm{~b}$ \\
\hline & $48 \mathrm{~h}$ & 4799 & 91 & 49 & 41 & 20 & 201 & $4,0 \mathrm{~b}$ \\
\hline & $\mathrm{CO}$ & 3998 & 320 & 277 & 213 & 192 & 1002 & $20,0 \mathrm{a}$ \\
\hline $\mathrm{D}$ & $24 \mathrm{~h}$ & 4602 & 199 & 144 & 24 & 31 & 398 & $8,0 \mathrm{~b}$ \\
\hline & $48 \mathrm{~h}$ & 4684 & 109 & 95 & 79 & 33 & 316 & $6,3 \mathrm{~b}$ \\
\hline & $\mathrm{CO}$ & 3938 & 299 & 313 & 297 & 153 & 1062 & $21,2 \mathrm{a}$ \\
\hline & $24 \mathrm{~h}$ & 4631 & 121 & 98 & 81 & 69 & 369 & $7,4 \mathrm{~b}$ \\
\hline & $48 \mathrm{~h}$ & 4699 & 139 & 44 & 99 & 19 & 301 & $6,0 \mathrm{~b}$ \\
\hline
\end{tabular}

A - Pepsico( ; B - Nestlé(); C - Maratá@); D - Piracanjuba@; E - Embaré@; TCII - Total de células em interfase e indiferenciadas; TE - Tempo de Exposição; CO - Controle; IM - Índice Mitótico; TCD - Total de células em divisão. Valores de IM seguidos da mesma letra dentro de um mesmo tratamento não diferem significativamente entre si, ao nível de $5 \%$, pelo teste $\chi 2$.

Tabela 2 -Número de alterações celulares observadas em tecido meristemático de raízes de Allium cepa tratados com achocolatados lácteos não fermentados de cinco empresas alimentícias, identificadas como A, B, C, D e E, nos tempos de análise 24 e 48 horas

\begin{tabular}{c|c|c|c|c|c|c}
\hline Empresa & TE & $\begin{array}{c}\text { Metáfase } \\
\text { colchicínica }\end{array}$ & Ponte anáfasica & Ponte telofásica & Micronúcleo & TAC \\
\hline & $\mathrm{CO}$ & 00 & 00 & 00 & 01 & $01 \mathrm{a}$ \\
\hline $\mathrm{A}$ & $24 \mathrm{~h}$ & 09 & 11 & 09 & 54 & $83 \mathrm{~b}$ \\
\hline & $48 \mathrm{~h}$ & 18 & 07 & 21 & 30 & $76 \mathrm{~b}$ \\
\hline & $\mathrm{CO}$ & 00 & 01 & 00 & 00 & $01 \mathrm{a}$ \\
\hline $\mathrm{B}$ & $24 \mathrm{~h}$ & 19 & 17 & 09 & 15 & $60 \mathrm{~b}$ \\
\hline & $48 \mathrm{~h}$ & 21 & 07 & 07 & 18 & $53 \mathrm{~b}$ \\
\hline & $\mathrm{CO}$ & 00 & 01 & 00 & 00 & $01 \mathrm{a}$ \\
\hline $\mathrm{C}$ & $24 \mathrm{~h}$ & 08 & 34 & 14 & 32 & $88 \mathrm{~b}$ \\
\hline & $48 \mathrm{~h}$ & 13 & 11 & 07 & 40 & $71 \mathrm{~b}$ \\
\hline & $\mathrm{CO}$ & 01 & 00 & 00 & 00 & $01 \mathrm{a}$ \\
$\mathrm{D}$ & $24 \mathrm{~h}$ & 23 & 15 & 00 & 22 & $60 \mathrm{~b}$ \\
& $48 \mathrm{~h}$ & 11 & 21 & 11 & 13 & $56 \mathrm{~b}$ \\
\hline & $\mathrm{CO}$ & 01 & 00 & 00 & 00 & $01 \mathrm{a}$ \\
$\mathrm{E}$ & $24 \mathrm{~h}$ & 19 & 13 & 03 & 19 & $54 \mathrm{~b}$ \\
& $48 \mathrm{~h}$ & 21 & 11 & 11 & 14 & $57 \mathrm{~b}$ \\
\hline
\end{tabular}

A - Pepsico@; B - Nestlé(); C - Maratá(; D - Piracanjuba@; E - Embaré@;TAC - Total de Alterações Celulares; TE - Tempo de Exposição; CO - Controle; Valores de TAC seguidos da mesma letra dentro de um mesmo tratamento não diferem significativamente entre si, ao nível de $5 \%$, pelo teste $\chi 2$. 


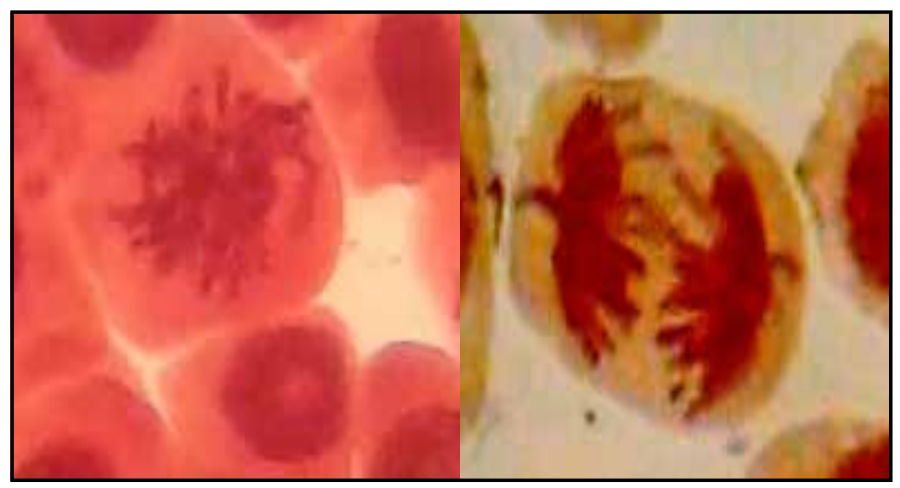

Figura 1 - Alterações de fuso mitótico, dos tipos Metáfase cochícinica e Ponte anafásica, observadas em tecido meristemático de raízes de Allium cepa tratado com achocolatados identificados como A, B, C, D, E, F

de aberrações de fuso mitótico e de células micronucleadas, e a detecção de neoplasias.

Ainda, a frequência de alterações celulares observadas na Tabela 2 corrobora aos resultados de redução da divisão celular descritos na Tabela 1. Aissa et al. (2012) relatam que metáfases com alinhamento incorreto de cromossomos na placa equatorial, as denominadas metáfases colchícinicas, assim como, cromossomos em atraso na anáfase e/ou telófase, conhecidas como pontes anáfasicas e telofásicas, resultam na formação de células com números cromossômicos distintos, bem como com alterações cromossômicas estruturais. Considerando que o princípio do ciclo celular é a formação de células idênticas, a produção de células com alteração na estrutura e/ou no número cromossômico, que tornam o funcionamento celular inviável, tendem a ser eliminadas de tecidos com desempenho normal.

Conforme mencionado anteriormente, não existem na literatura científica, até o momento, trabalhos de avaliação toxicológica em nível celular referentes a bebidas lácteas industrializadas não fermentadas. Entretanto, são encontrados trabalhos de avaliação de citotoxicidade de alguns dos constituintes químicos das classes de aditivos alimentares presentes na formulação destes alimentos, conforme descrito em documento técnico que regulariza tais produtos (Brasil, 2000). Porém, é de grande importância mencionar que a composição química de achocolatados lácteos, como os avaliados no presente estudo, é permitida e assegurada pela legislação brasileira (Brasil, 2000; Pflanzer et al., 2010) e internacional (Pflanzer et al., 2010).

Dentre os edulcorantes encontrados nestes achocolatados estão o aspartame, o ciclamato de sódio, o acesulfame de potássio e a sacarina sódica. Van EyK (2015), verificaram, por meio das linhagens celulares Caco-2 (células de colón), HT-29 (células de cólon) e HEK-293 (células de rim), que estes edulcorantes foram citotóxicos, genotóxicos e mutagênicos as células estudadas. Corroborando aos resultados destes pesquisadores, Sasaky et al. (2012), através do teste do cometa, observaram que o sacarina sódica e o ciclamato de sódio foram genotóxicos e mutagênicos as células de cólon de roedores.

Ainda, na formulação química destes produtos lácteos encontra-se o aditivo de aroma e sabor sintético artificial de chocolate, aditivo que reforça o aroma de cacau em pó presentes nas bebidas lácteas achocolatadas. Marques et al. (2015) avaliaram a toxicidade em nível celular de aromatizantes de chocolates e verificaram que este microingrediente alimentar reduziu drasticamente a divisão celular e causou aberrações celulares a meristemas de A. cepa. Da mesma forma, Sales et al. (2016) avaliaram a ação de aromatizantes de chocolates em medula óssea in vivo de camundongos, e verificaram que estes aromatizantes causaram redução na maturação de eritrócitos e induziram a formação de micronúcleos no tecido hematopoiético avaliado, mostrando-se citotóxicos e mutagênicos.

Os resultados de toxicidade em nível celular obtidos aqui com os achocolatados corroboram aos resultados de citotoxicidade, genotoxicidade e mutagencidade observados para os edulcorantes aspartame, ciclamato de sódio, acesulfame de potássio e sacarina sódica, e para o aromatizante de chocolate.

\section{Conclusão}

Os resultados de citotoxicidade e genotoxicidade de amostras de achocolatados lácteos do tipo não fermentados obtidos no presente estudo, aliados aos dados de toxicidade em nível celular de aditivos alimentares presentes na formulação básica de bebidas lácteas achocolatadas, sinalizam a urgente necessidade de avaliações mais detalhadas, em sistemas testes com maior nível de complexidade, para que se possa estabelecer com segurança a toxicidade em nível celular desses alimentos, e assegurar a saúde de quem os consome. 


\section{Referências}

Aissa AF, Bianchi MLP, Ribeiro JC, Hernandes LC, Faria AF, Mercadante AZ et al. Comparative study of $\beta$-carotene and microencapsulated $\beta$-carotene: Evaluation of their genotoxic and antigenotoxic effects. Food Chem. Toxicol. 2012;50(5): 1418-1424. Doi: 10.1016/j.fct.2012.02.030

Batista MA, Gama LLA, Almeida LPD, Ornellas CBD, Santos, LCD, Silvestre, MPC. Development, characterization and sensory analysis of food preparations for children containing whey proteins or albumin. Braz. J. Food Techn. 2015;8(1): 31-41. Doi: 10.1590/1981-6723.3214

Bianchi J, Mantovani MS, Marin-Morales MA. Analysis of the genotoxic potential of low concentrations of Malathion on the Allium cepa cells and rat hepatoma tissue culture. J. Environ. Sci. 2015;36:102-111. Doi: 10.1016/j.jes.2015.03.034

Brasil. Ministério da Agricultura e Abastecimento. Regimento Interno da Secretaria, aprovado pela Portaria Ministerial no 574, de 8 de dezembro de 2000. Disponível em: http:/www.engetecno.com.br/port/legislacao/ leite_rtfiq_beb_lacteas.htm. Acesso em: 22 junho, 2016.

Corcuera LA, Vettorazzi A, Arbillaga L, Pérez N, Gi AG, Azqueta A et al. Genotoxicity of Aflatoxin B1 and Ochratoxin A after simultaneous application of the in vivo micronucleus and comet assay. Food. Chem. Toxicol. 2015;76:16-124. Doi: doi:10.1016/j.fct.2014.12.003

Gomes KMS, Oliveira MVGA, Carvalho FRS, Menezes CC, Peron AP.Citotoxicity of food dyes sunset yellow (E110), bordeax red (E-123), and tatrazine yellow (E-102) on Allium cepaL. root meristematic cells. Food Sci. Techn. 2013;33(1): 218-223. Doi: 10.1590/S0101-20612013005000012

Guerra M, Souza MJ. Como observar os cromossomos: um guia de técnicas em citogenética vegetal, animal e humana. Ribeirão Preto: FUNPEC; 2002.

Herrero O, Martín JP, Freire PF, López LC; Peropadre A, Hazen MJ.Toxicological evaluation of three contaminant of emerging concern by use of Allium cepa test. Mut. Res. 2011;743:24-34. Doi: 10.1016/j.mrgentox.2011.12.028

Lacerda LP, Malaquias G, Peron AP. Antiproliferative action of aqueous extracts of Hymenaea stigonocarpa Mart. (Fabaceae) on the cell cycle of Allium cepa L. An. Acad. Bra. Ciên. 2014;89(3): 1147-1150. Doi: 10.1590/00013765201420130163

Mirtem GC, Victora CG, Costa, RL. Fatores associados com conhecimento e preferências alimentares em crianças de 3-9 anos na cidade de Pelotas, Brasil. J. Healt Biol. Sci.2013;1(1):27. Doi: 10.12662/2317-3076jhbs.v1i1.14.p27.2013

Moura AG, Santana GM, Ferreira PMP, Sousa JMC, Peron AP. Cytotoxicity of Cheese and Cheddar Cheese food flavorings on Allim cepa L root meristems. Braz J Biol.76(2): 439-443, 2016. Doi: 10.1590/6484.20514

Neves ES, Ferreira PMP, Lima LH, Peron AP. Action of aqueous extracts of Phyllanthus niruri L. (Euphorbiaceae) leaves on meristematic root cells of Allium cepa L. An. Acad. Bras. Ciên. 2014;86(3):1131-1137. Doi: 10.12662/23173076jhbs.v1i1.14.p27.2013

Oliveira JM, Castro IRRD, Silva GB, Venancio SI, Saldiva, SRDM. Assessing complementary feeding practices in the first two years of life: a proposal for indicators and a monitoring tool. Cad. Saúde Pública 2015;31(2): 377-394. Doi: 10.1590/0102-311X00209513

Oliveira MA, Silva PHS, Gois FN, Carvalho MF, Oliveira IARR. A importância do controle das condições microbiológicas e higiênico sanitárias na prevenção de doenças transmitidas por alimentos-uma revisão de literatura. REC 2016;REC 1(1): s/n.

Oliveira, MVA, Alves DDL, Lima LHGM, Castro JMC, Peron, AP. Cytotoxicity of erytrosine (E-127), brilliant blue (E-133) and red 40 (E-129) food dyes plant test system. Acta Scien. Biol. 2013;5(4): 557-562. Doi: 10.4025/actascibiolsci. v35i4.18419 
Pflanzer SB, Cruz AGD, Hatanaka CL, Mamede PL, Cadena R, Faria JAF et al. Perfil sensorial e aceitação de bebida láctea achocolatada. Food Sci. Technol. 2010;30(2):391-398. Doi: 10.1590/S0101-20612010000200016

Queiroz FMD, Matias KWDO, Cunha MMFD, Schwarz, A. Evaluation of (anti) genotoxic activities of Phyllanthus niruri L. in rat bone marrow using the micronucleus test. Braz. J. Pharm. Sci. 2013;49(1):135-148. Doi: 10.1590/ S1984-82502013000100015

Sales IMS, Peron AP. Toxicity of synthetic flavorings, nature identical and artificial, to hematopoietic tissue cells of rodents. Braz. J. Biol. 2016; No prelo.

Santana GM, Deus MSM, Sousa JMC, Ferreira, PMP, Fernandes HB, Peron AP. Antimitotic and antimutagenic action of the Hymenaea stigonocarpa bark on dividing cells. Braz. J. Biol. 2016;76(2): 520 - 525. Doi: 10.1111/1471-0307.12227

Tabrez S, Sahkil S, Urooj M, Damanhori GA, Abuzenadah AM, Ahmad D. Genotoxicity testing and biomarker studies on surface water: an over view of the techniques and their efficacies. J. Environ. Sci. Health 2011;29(3):250275. Doi: 10.1080/10590501.2011.601849.

Türkoğlu, Ş. Genotoxicity of five food preservatives tested on root tips of Allium cepa L. Mut Res. 2007;626:4-14. Doi: 10.1016/j.mrgentox.2006.07.006

Valavanidis A, Vlachogianni A, Fiotakis K, Loridas S. Pulmonary oxidative stress, inflammation and cancer: respirable particulate matter, fibrous dusts and ozone as major causes of lung carcinogenesis through reactive oxygen species mechanisms. Intern. J. Environ. Res. Publ. Health 2013;10(9):3886-3907. Doi:10.3390/_ijerph10093836

Van Eyk AD. The effect of five artificial sweeteners on Caco-2, HT-29 and HEK-293 cells. Drug Chem. Toxicol. 2015;38(3):318-327. Doi:10.1080/01635581.2012.683227

Zaineddin AK, Buck K, Vrieling A, Geinz J, Flesch-Janys D, Linseisen J et al. The association between dietary lignans, phytoestrogen-rich foods, and fiber intake and postmenopausal breast cancer risk: a German case-control study. Nut. Cancer 2012;64(5):652-665.

Zilifdar F, Alper-Hayta S, Yilmaz S, Kaplan-Özen Ç, Foto E, Aydoğan Z et al. Genotoxic potentials and eukaryotic DNA topoisomerase I inhibitory effects of some benzoxazine derivatives. Med. Chem. Res. 2014;23(1):480-486. Doi: 100.1007/s00044.013.0658.5 